\title{
COMPREENSÃO SOBRE O ENVELHECIMENTO E AÇÕES DESENVOLVIDAS PELO ENFERMEIRO NA ATENÇÃO PRIMÁRIA À SAÚDE
}

\author{
COMPREHENSION ON THE AGING AND ACTIONS TAKEN \\ BY NURSE IN PRIMARY HEALTH CARE
}

\section{COMPRENSIÓN SOBRE EL ENVEJECIMIENTO Y ACCIONES ADOPTADAS POR LA ENFERMERA EN ATENCIÓN PRIMARIA DE SALUD}

\author{
Calíope Pilger * \\ Janaina Fernanda Dias ${ }^{* *}$ \\ Carla KanaWaVA ${ }^{* * *}$ \\ TATIANE BARATIERI ${ }^{* * *}$ \\ LigIa CARREIRA ${ }^{* * * *}$
}

\begin{abstract}
RESUMO
O estudo objetivou compreender a percepção do enfermeiro sobre o processo do envelhecimento e identificar as ações desempenhadas pela enfermagem. Foram sujeitos do estudo, enfermeiros que pertenciam à secretaria municipal de saúde de um município do Centro Oeste do Paraná. O período de coleta de dados foi nos meses de junho e julho de 2009, por meio de entrevistas semiestruturada contendo duas questões norteadoras. Para análise dos dados foi utilizada a análise de Bardin. Para os sujeitos da pesquisa, o envelhecimento caracteriza-se pela depreciação progressiva da capacidade de adaptação e de reserva biológica do organismo, em que a perda das funções biológicas, alterações psicológicas e sociais estão ligadas diretamente a qualidade de vida e ao bem estar do idoso, influenciando na habilidade ou capacidade para desempenhar tarefas ou atividades da vida diária. Em algumas unidades básicas de saúde há uma ausência de ações primárias realizadas pelos enfermeiros e quando existentes são de iniciativa da própria população, ou ainda delegadas a outros profissionais de saúde. Conclui-se que os enfermeiros conhecem o processo de envelhecimento mais no âmbito biológico, ficando algumas ações de saúde sobre a supervisão de outros profissionais ou até mesmo da comunidade não mantendo contato diário e contínuo com essa e com os idosos.
\end{abstract}

Palavras chave: Envelhecimento, enfermagem, atenção primária à saúde.

\footnotetext{
ABSTRACT

The study aimed to understand the perceptions of nurses about the aging process as well as identify the actions performed by the nurses. Subjects of the study were the nurses who belonged to the municipal health department

*Enfermeira. Docente da Universidade Estadual do Centro Oeste - UNICENTRO. E-mail: caliopepilger@hotmail.com.

** Enfermeira da Secretaria de Saúde do Municipio de Guarapuava-PR-BR. E-mail: jfernandinha@hotmail.com.

${ }^{* * *}$ Enfermeira da Secretaria de Saúde do Municipio de Pariqueraçu-SP-BR. E-mail: carlakanawava@hotmail.com.

${ }^{* * * *}$ Enfermeira. Docente da Universidade Estadual do Centro Oeste - UNICENTRO Guarapuava - PR- BR. E-mail: baratieri. tatiane@gmail.com.

${ }^{* * * * *}$ Enfermeira. Professora Adjunta da Universidade Estadual de Maringá - Maringá. E-mail: ligiacarreira@hotmail.com.
} 
of a Midwestern city of Paraná. The period of data collection took place in June and July of 2009, through semistructured interviews with two guiding questions. For data analysis, the Bardin analysis was used. For the study subjects this process is characterized by the progressive depreciation of adaptability and biological reserve of the organism in which the loss of biological functions psychological and social changes are directly linked to quality of life and well being of the elderly, influencing the ability or capacity to perform tasks or activities of daily living. In some primary health care settings is a lack of primary actions performed by nurses and when they are available it is population initiative, or delegated to other health professionals. It was concluded that nurses know the aging process mostly in the biological aspect, getting some action under other health professionals supervision or even from the community not maintaining daily contact and continuing with this and with the elderly.

Key words: Aging, nursing, primary health care.

\section{RESUMEN}

El estudio tuvo como objetivo comprender las percepciones de las enfermeras sobre el proceso de envejecimiento e identificar las acciones realizadas por las enfermeras. Fueron sujetos del estudio, las enfermeras que pertenecen al departamento de salud municipal de una ciudad del medio oeste del Paraná. El período de recolección de datos tuvo lugar entre junio y julio de 2009, a través de entrevistas semiestructuradas con las preguntas orientadoras. Para el análisis de datos se utilizo el análisis de Bardin. Para los sujetos de estudio el proceso de envejecimiento se caracteriza por la disminución progresiva de la capacidad de adaptación y la reserva biológica del organismo, en la que se observan directamente la pérdida de las funciones biológicas, cambios psicológicos y sociales relacionados con la calidad de vida y el bienestar de las personas mayores, que influyen en la aptitud o capacidad para realizar tareas o actividades de la vida diaria. En algunas unidades básicas de salud hay una falta de acciones primarias realizadas por los enfermeros y cuando existen son de iniciativa de la propia población, o delegadas a otros profesionales de salud. Se concluye que los enfermeros conocen el proceso de envejecimiento más en los aspectos biológicos, dejando actividades de salud bajo la supervisión de otros profesionales o incluso de la comunidad sin mantener contacto diario y continuo con las personas mayores.

Palabras clave: Envejecimiento, enfermería, atención primaria de salud.

Fecha recepción: 17/08/11 Fecha aceptación: 20/12/12

\section{INTRODUÇÃO}

O crescimento da população idosa é um fenômeno mundial e no Brasil. As modificações ocorrem de forma rápida, com real impacto na sociedade, sendo que as alterações da pirâmide etária, com relação à população brasileira é um fenômeno de sua própria dinâmica que vem ocorrendo ao longo das últimas décadas (1).

Na população de 60 anos ou mais houve crescimento de 697 mil pessoas entre 2008 e 2009, o que representou um aumento de
3,3\%, contra uma elevação de $1 \%$ no total da população residente do país. Em 2009, 11,3\% dos brasileiros tinham 60 anos ou mais de idade, frente a $11,1 \%$ em 2008 e 9,7\% em 2004. Atualmente, segundo resultados dos estudos da Pesquisa Nacional por Amostra de Domicílios (PNAD), os idosos brasileiros somam 23,5 milhões, mais que o dobro do registrado em 1991, quando a faixa etária contabilizava 10,7 milhões de pessoas (2).

$\mathrm{O}$ envelhecimento pode ser entendido como um processo, dinâmico, progressivo e comum a todos os seres humanos que depende e é influenciado por vários fatores 
(biológicos, econômicos, psicológicos, sociais, culturais, entre outros) conferindo a cada um que envelhece características específicas, que pode interferir na capacidade de adaptação do indivíduo ao meio social em que está inserido, tornando-o mais vulnerável aos agravos e doenças, comprometendo sua qualidade de saúde (3).

É importante que a atenção ao idoso volte-se principalmente às suas reais necessidades, seja elas, fisiológicas, emocionais, sociais e espirituais. Emerge assim, a necessidade de a equipe de saúde, em especial dos enfermeiros, conhecerem como o idoso experimenta seu envelhecimento para que assim a assistência seja pautada na recuperação, manutenção e promoção da autonomia e independência por meio do desenvolvimento de ações de saúde individuais e coletivas. Visto que, as ações em saúde para o idoso devem objetivar, ao máximo, a manutenção do idoso na comunidade, junto à sua família, da forma mais digna e confortável possível (4).

Além de conhecer o idoso em toda sua particularidade, cada profissional precisa refletir sobre sua própria percepção sobre o processo de envelhecimento. Haja vista que, a equipe de enfermagem possui como atribuição o cuidado do ser humano em todo o processo de viver e morrer, incluindo a velhice, que é uma fase ainda tão marcada por preconceitos e tabus. E saber intervir diante dos problemas que afetam o idoso exige do enfermeiro conhecimentos, habilidades específicas acerca do processo de envelhecimento, principalmente a respeito do cuidado, que inclui a família e as dificuldades enfrentadas durante esta fase (5).

Com o avanço da idade há limitação nas funções fisiológicas do corpo, tornando os idosos cada vez mais predispostos à dependência para realização de autocuidado, à perda de autonomia e qualidade de vida, e, desta maneira, se tornam mais susceptíveis a doenças crônicas degenerativas, a qual, os profissionais de saúde, devem atuar na prevenção de agravos, promoção e recuperação da saúde, podendo evitar assim o surgimento ou piora dessas doenças (6).

As ações e programas que envolvem a atenção primária de saúde necessitam serem capazes de identificar variáveis que podem interferir direta ou indiretamente no processo de envelhecimento, como a identificação e avaliação das mudanças biopsicossociais, seja por meio da consulta de enfermagem, da abordagem de questões referentes ao autocuidado, imunização e informações sobre o uso correto de medicamentos, entre outras ações de prevenção de agravos e promoção da saúde (5).

Com base no exposto, o presente estudo tem como objetivo compreender a percepção do enfermeiro atuante na saúde pública sobre o processo de envelhecimento e identificar as ações que estes profissionais realizam para o bem estar biopsicossocial do idoso do município de Guarapuava-PR.

\section{METODOLOGIA}

Estudo exploratório, com abordagem qualitativa descritiva, que nos permitiu uma interação com os sujeitos da pesquisa, objetivando conhecer a percepção dos enfermeiros sobre o processo de envelhecimento e as ações desempenhadas por esse profissional frente às mudanças biopsicossociais nos Centros Integrados de Atendimento (CIA's).

A pesquisa foi realizada nos dez CIA's do município de Guarapuava, os quais são responsáveis pela promoção da saúde, prevenção e tratamento de agravos no âmbito da atenção primária, juntamente com a Estratégia de Saúde da Família (ESF). Porém, os CIA's integram um modelo de saúde municipal, no qual desenvolve-se cuidados específicos aos idosos, proporcionando um atendimento integral através das especialidades médicas e equipe multiprofissional, sendo esta composta por enfermeiros, médicos, fisioterapeutas, nutricionistas, dentistas, en- 
tre outros, abarcando nestes centros todas as unidade de ESF, e, por essa razão, foram escolhidos como locais deste estudo.

Para participar da pesquisa foi escolhido o profissional enfermeiro, tendo em vista que esse é o gerente da unidade de saúde, e portanto, quem melhor conhece a dinâmica assistencial e gerencial dos referidos CIA's, tendo como critérios de inclusão ser vinculado à Secretária Municipal de Saúde de Guarapuava; trabalhar por no mínimo seis meses na mesma unidade de saúde, tempo esse necessário para o profissional apreender a dinâmica de trabalho. Desse modo, fizeram parte do estudo dez enfermeiros, sendo que não houve exclusão de nenhum sujeito.

Os dados foram coletados nos meses de junho e julho de 2009, sendo para isso utilizado o método da entrevista, que foi realizada pela aplicação de um instrumento semiestruturado, o qual continha duas questões norteadoras "O que você entende sobre o processo de envelhecimento?" e "O que a equipe unidade de saúde faz para obter uma melhor qualidade de vida para a pessoa idosa?". O questionário foi elaborado pelas pesquisadoras e avaliado no conteúdo e aparência por três professores doutores da área de estudos qualitativos de uma universidade pública do Paraná. As falas dos respondentes foram gravadas após consentimento do mesmo e, posteriormente, transcritas na íntegra, sendo sua transcrição conferida pelos enfermeiros entrevistados para confirmação de seu conteúdo.

A análise dos dados foi realizada por meio da análise de conteúdo categorial de Bardin, na qual se buscou os núcleos de sentido que compõem a comunicação, cuja frequência teve sentido para o objeto analítico visado. Essa análise temática permite maior compreensão do texto, fazendo emergir a ideia central e as secundárias, as unidades e subunidades de pensamento, sua correlação e a forma pela qual esta se dá (7). A análise dos dados foi realizada pelo pesquisador doutor e pelos mestres, autores do estudo.
Esta pesquisa foi realizada após a autorização da Secretaria Municipal de Saúde e aprovação do Comitê de ética em Pesquisa da Universidade Estadual do Centro Oeste - UNICENTRO, com número do parecer $13158 / 2008$, e os sujeitos que concordaram em participar do estudo leram e assinaram o termo de consentimento livre e esclarecido (TCLE).

Para preservar o anonimato das participantes, as entrevistas foram identificadas por codinomes de flores: Orquídea, Lírio, Rosa, Tulipa, Violeta, Girassol, Margarida, Hortência, Petúnia e Azaléia. Foi escolhido o nome de flores para os depoentes, pelas características subjetivas que a pesquisa qualitativa exige em sua estruturação.

\section{RESULTADOS E DISCUSSÃO}

Diante dos dados colhidos na presente pesquisa, buscamos compreender a percepção dos enfermeiros sobre o processo de envelhecimento, o qual corrobora com a literatura (8), no que se refere ao processo de envelhecimento enquanto parte da vida, constituindo um fenômeno multifatorial e variando conforme os tempos históricos, as diversidades culturais, classes sociais, histórias de vida pessoais, condições educacionais, estilos de vida, os gêneros, profissões e etnias, o que afeta o indivíduo de modo muito particular. A partir dessa compreensão surgiram três categorias baseadas na percepção do enfermeiro com relação ao processo de envelhecimento: $\mathrm{O}$ processo de envelhecimento na perspectiva biológica; $\mathrm{O}$ processo de enfermagem na perspectiva psicológica; e o Processo de enfermagem na perspectiva sóciofamiliar. Outra categoria denominada "Ações desenvolvidas pelo enfermeiro na Atenção Primária de Saúde" emergiu na identificação das atividades desenvolvidas pelos enfermeiros na Atenção Primária à Saúde com foco no bem estar da pessoa idosa. 


\section{O processo de envelhecimento na perspectiva biológica}

Cada enfermeiro relatou sua percepção sobre o processo de envelhecimento basicamente definindo como um fato da própria natureza, em que há princípio e fim. O termo envelhecer nos organismos vivos remete aos efeitos das alterações biológicas que no organismo vivo é implacável, ativo e irreversível, causando mais vulnerabilidade do organismo às agressões externas e internas. Existem evidências de que o processo de envelhecimento é de natureza multifatorial e dependente da programação genética e das alterações que ocorrem em nível celular-molecular (9).

Os sujeitos da pesquisa salientaram que as mudanças enfáticas no processo de envelhecimento são as biológicas, por serem mais visíveis onde ocorre uma diminuição da capacidade funcional, como observamos nas falas a seguir:

"[...] O processo de envelhecimento é uma etapa onde há uma diminuição da capacidade de funções e mobilidade. Ocorrem mudanças nos órgãos, nas células, mudanças assim; biológicas. Eu acho que é isso" (Rosa).

"[...] O envelhecimento são diversos fatores que acontecem desde o nascimento. As nossas células vão amadurecendo e a partir da idade cronológica, iniciado pelo processo de envelhecimento, tendo como principais mudanças as alterações físicas que podem alterar o estado de saúde do idoso" (Tulipa).

O envelhecimento biológico é mencionado como uma fase em que o organismo apresenta perdas funcionais. Porém, essa etapa da vida é muito mais complexa do que as mudanças celulares ou ao fato do organismo estar "debilitado", de modo que é um processo biológico inevitável, caracterizado por declínio geral das funções fisiológicas, isto é contrabalançado por reparo e fatores de ma- nutenção que contribuem para a longevidade do organismo.

Visto que o envelhecimento fisiológico compreende uma série de alterações nas funções orgânicas devido exclusivamente aos efeitos da idade avançada sobre o organismo, fazendo com que o mesmo perca a capacidade de manter o equilíbrio homeostático e que todas as funções fisiológicas gradualmente comecem a declinar, contribuindo assim para a redução da funcionabilidade do idoso e o aparecimento de doenças crônicas (10). Assim, esse fenômeno tem considerável predominância na população idosa, em virtude das alterações decorrentes do processo de envelhecimento, como citado pelo profissional:

“[...] Eu acho que principalmente o processo de envelhecimento é marcado por alterações sistêmicas, aquelas que são biológicas como a pele que se torna mais seca, rugosa e flácida, os melanócitos diminuem em número e sofrem alterações funcionais, a pele torna-se mais delgada; além dos ossos que ficam mais fracos, o sistema nervoso que causa diminuição dos reflexos e também o sistema cardiovascular que é um dos principais causas de alterações que vemos aqui na unidade, como a hipertensão e também tem a diabetes que é muito comum" (Hortência).

A maioria das doenças crônicas que acomete o indivíduo idoso tem, na própria idade, seu principal fator de risco. Envelhecer independentemente da presença de doença(s) crônica(s) é uma realidade atual que precisa ser vista, de maneira técnica, pela equipe de saúde que presta assistência ao idoso (11).

\section{O processo de envelhecimento na perspectiva psicológica}

Diante da visão do envelhecimento, existem percepções distintas entre as pessoas; algumas percebem a velhice como um período vazio, sem valor, no qual existe inutilidade, 
declínio e falta de sentido, enquanto que, para outros, pode ser um período de aproveitamento, crescimento, realização pessoal, oportunidade para fazer aquilo que não fez quando jovem, porque o tempo foi todo ocupado na criação dos filhos, na busca de estabilidade, entre outras atividades (11).

Com relação ao acúmulo de experiência e maturidade na velhice alguns depoentes expressam essa percepção por meio das falas a seguir:

“[...] É a pessoa idosa também possui durante o processo de envelhecimento, mudanças na forma de pensar, assim, ela pensa muito mais antes de tomar decisões, ela é bem mais madura. Isso ocorre porque ela é mais experiente, é uma característica desse processo" (Azaléia).

“[...] O idoso também se torna muito mais experiente, com uma forma de pensar mais madura, tanto nas suas questões, nas suas decisões, ele resolve de uma forma mais tranquila. E às vezes ter que ter paciência, o que a gente chama de empatia, pois conformem às mudanças deste processo o psicológico do idoso fica mais sensível" (Hortência).

Nesta perspectiva de velhice, o idoso se torna mais experiente, considerando que o padrão de comportamento adquirido e mantido ao longo da vida tem uma influência direta na forma de pensar do idoso, estes são resultados de uma construção, proporcionada com o passar dos anos. Assim, na assistência ao idoso é de suma importância que o enfermeiro atenda às necessidades específicas do idoso por meio de uma visão holística, de modo a estabelecer uma boa relação e expressar sua atenção, atendendo com dignidade e respeito, e, essencialmente, levar em consideração para o planejamento de suas ações os valores, as vivências e as contribuições do idoso (12), ou seja, considerar a experiência e a sabedoria adquirida dessa população ao longo da vida.

Os enfermeiros enfatizam que concomi- tante ao processo de transformação biológica na maturidade, ocorrem também alterações psicológicas:

“[...] Eu vejo a velhice como uma etapa da vida que ocorre mudanças no emocional. Podemos ver quando idoso vêm no posto, eles gostam de conversar, querem mais atenção e conforme vai envelhecendo se torna mais carente. Isso é bem evidente, mais é algo mais psicológico, nada fisico"(Tulipa).

“[...] Os idosos também passam por alterações psicológicas, a qual eles podem ter transtornos emocionais devido às mudanças que ocorrem no processo de envelhecimento. Essas mudanças podem manifestar-se por uma mágoa, agressividade, dependência, abandono, fracasso, frustrações perda de papel social que é muito comum vergonha e por ai vai" (Lírio).

As mudanças psicológicas e seu impacto no cotidiano e o estilo de vida do idoso são manifestados, muitas vezes, por sentimentos como frustrações, fracasso e o aparecimento de doenças emocionais, como a depressão, segundo a percepção dos enfermeiros.

As alterações psicológicas surgem em decorrência de diversos fatores que podem conduzir ao engrandecimento ou ao esgotamento do idoso. Com o envelhecimento, as habilidades verbais, a memória e a atenção se deterioram mais facilmente, ao passo que as habilidades numéricas, a capacidade imaginativa e de julgamento permanecem quase que intactas. Em virtude destas associações, não só os profissionais da saúde, bem como todos aqueles que lidam com o idoso, precisam ter a preocupação de tratá-lo com maior atenção, paciência e perseverança, a ponto de minorar as limitações que cada um apresenta.

A depressão se constitui em um transtorno que afeta o organismo como um todo, o qual compromete o físico, o humor e, em consequência, o pensamento do idoso. A depressão é um dos transtornos psiquiátricos 
mais comuns entre os idosos, sendo pouco diagnosticada e tratada, e tem fortes impactos negativos na qualidade de vida, pois a pessoa se sente insatisfeita, priva-se das relações interpessoais, e, consequentemente, reduz sua expectativa de vida, seja por meio do suicídio ou de doenças somáticas relacionadas à depressão (13).

A vivência do enfermeiro no cuidado ao idoso na atenção primária aponta a depressão como uma das principais características das alterações emocionais acometidas nesta população, como observamos a seguir:

“[...] Já quando pensamos nas alterações psicológicas vemos que as pessoas ficam mais sensiveis e as mudanças são muitas neste processo, econômicas e de estresse que deixa o idoso bem vulnerável a adquirir uma doença vulnerável como a depressão" (Orquídea).

"[...] O processo de envelhecimento altera também o emocional do idoso, ele pode se sentir deprimido, pode surgir à depressão, isso depende de vários fatores que estão relacionados às suas situações do dia-a-dia" (Rosa).

As alterações emocionais e o surgimento da depressão foram relacionados aos diversos fatores presentes no dia a dia do idoso, tais como as perdas econômicas, físicas e cognitivas, que podem se manifestar por transtornos emocionais, entre eles: a mágoa, depressão, agressividade, dependência, abandono, sensação de fracasso, humilhação, vergonha, perdas, frustrações, bem como a reflexão sobre a própria vida.

$\mathrm{Na}$ avaliação do estado psicológico do idoso faz-se necessário observar se ele sente-se amado, respeitado, útil, e envolvido em atividades físicas, sociais e ocupacionais. As condições familiares, a independência, autonomia, vida saudável, alimentação, sono, atividades de lazer, como grupos de convivência, passeios e os bons relacionamentos são fatores que promovem a qualidade de vida do idoso e seu equilíbrio emocional (8).
E esta etapa da vida caracterizada como velhice, possui suas peculiaridades e singularidades e só pode ser compreendida a partir da relação que se estabelece entre os diferentes aspectos cronológicos, biológicos, psicológicos e sociais. Essa interação institui-se de acordo com as condições da cultura na qual o indivíduo está inserido (14).

\section{O processo de envelhecimento na perspectiva sócio-familiar}

A condição social também integra o processo de envelhecimento e a mudança de papéis sociais é uma das principais características percebidas pelos sujeitos da pesquisa. Pensando neste contexto, a aposentadoria entra como principal modificador, uma vez que essas atividades geralmente determinam as condições de vida social e econômica, bem como as relações sociais e o acesso ao lazer.

Afirma-se o exposto, tendo em vista que a aposentadoria é um fenômeno historicamente recente e teve seu surgimento com o advento da sociedade industrial, na forma de direito adquirido pelos trabalhadores. A passagem do trabalho ao repouso, característica da sociedade contemporânea vem acompanhada de algumas modificações que norteiam profundamente a vida das pessoas, isto é, quando se aposenta e deixa de ser economicamente ativa (14). Diante dessa nova fase de vida, o indivíduo se conscientiza de tal condição e é levado a assumir mudanças, passando por uma reestruturação de seu meio social, principalmente no que diz respeito à identidade do aposentado (9).

Podemos observar, a seguir, nos relatos dos entrevistados, que ocorrem modificações significativas com a chegada da aposentadoria, devido às circunstâncias em que se encontravam, visto que trabalhadores assalariados e com horários fixos, passam a não ter mais uma rotina diária de trabalho e um papel na sociedade:

“[...] Com esse processo vem à aposentadoria 
que faz com que perca um elo com as pessoas que trabalhavam. Dessa forma, a aposentadoria frequentemente é acompanhada pela perda do papel profissional e pelo afastamento da função" (Petúnia).

“[...] Eles já consideram que estão no término da vida profissional deles quando entram no processo de aposentadoria. Eles começam a sentir falta das suas atividades anteriores e surgem dores sem explicação devido a não estar onde costumava" (Azaléia).

Os enfermeiros apontam a aposentadoria como um período que o idoso passa a considerar como término de sua vida social produtiva, levando a perceber que os interesses comerciais e econômicos se tornam mais importantes do que outras necessidades humanas.

A aposentadoria se constitui em um dos principais fatores para alterações psicológicas e de inserção social, tendo em vista que vem incutida de uma desvalorização social do idoso, podendo se constituir na perda da identidade profissional, além de ser um episódio que faz com que o indivíduo a associe a chegada da velhice e da vida economicamente improdutiva. Desse modo, se durante a vida a pessoa desenvolve outras maneiras de satisfação além do trabalho, o enfrentamento de sua identidade durante a fase do envelhecimento é facilitado, caso contrário pode haver reflexos na estrutura psíquica (15).

Nesse âmbito, é necessário evitar que o idoso sofra com o isolamento social, proporcionando-lhe convívio familiar e comunitário, propiciando a constituição e manutenção de relações sociais, como observamos nas falas a seguir:

"[...] Com a mudança social o idoso também vê a família como tudo o que tem e ainda depositam suas expectativas, que não podia desfrutar, pois antes tinha outra rotina como trabalho e outras coisas, agora a família é essencial para ele" (Orquídea).
“[...] Há uma grande mudança na casa do idoso, ele passa a ter quer seguir uma rotina que não era dele, a família muda a visão sobre ele, $e$ isso pode gerar coisas ruins para o idoso, pois a família é um fator importante durante a transição do idoso nesta fase" (Tulipa).

O ambiente familiar também foi compreendido como determinante nas características e no comportamento do idoso. Por isso, a família possibilita o crescimento de todos, incluindo o idoso, pois cada um de seus membros possui funções, papéis, lugares, posições e as diferenças devem ser respeitadas e levadas em consideração. Em ambientes onde há falta de respeito e não reconhecimento de limites, o relacionamento é carregado de frustrações, com indivíduos deprimidos e agressivos. O idoso torna-se isolado socialmente e com medo de cometer erros e ser punido, e a família representa um refúgio para os idosos nesta nova fase de suas vidas, na qual depositam suas expectativas em novo contexto que antes não era possível em função do trabalho.

Mais do que em qualquer outra fase ao longo do curso de vida, o idoso precisa de uma relação direta, estreita e permanente com a família. Esta é o eixo de significância para seu cotidiano. Desta forma ele espera manter os espaços vitais que lhe permitam privacidade, aconchego e preservação da sua história (16).

Nesse âmbito, é necessário encontrar alternativas para manter o convívio social e o envolvimento com a família, propiciando maior interação do idoso com a sociedade. Entretanto, no contexto familiar existe, frequentemente, histórico de conflitos não resolvidos, entre os cônjuges, pais, filhos e irmãos, que pesam sobre o relacionamento atual; dependências de drogas e de alcoolismo; lembranças de violências praticadas pelos idosos no passado. É importante acrescentar a esse quadro, os problemas que surgem na família devido ao aumento da dependência do idoso, sobretudo aqueles resul- 
tantes de demências (8).

É essencial que os profissionais de saúde entendam o processo de envelhecimento de modo integral, sabendo intervir nas mudanças biológicas, psicológicas e sociais, realizando uma assistência adequada. Os cuidados para a pessoa idosa devem visar à manutenção de seu estado de saúde, expectativa de vida ativa, independência funcional e autonomia máxima possível, sendo necessária educação permanente de profissionais, aprimoramento de processos, procedimentos e acompanhamento do idoso, família e/ ou cuidador.

Ainda defende-se a hipótese de que por meio de treinamento ou capacitações busca-se melhorar não só a formação, mas as atitudes dos profissionais de saúde de modo que possam avaliar e tratar as condições que afligem pessoas idosas, fornecendo-lhes ferramentas e fortalecendo-as na direção de um envelhecimento saudável (11).

A assistência dos profissionais de saúde com relação ao processo saúde-doença, deve direcionar as ações para a promoção da qualidade de vida das pessoas em todos os ciclos vitais. No envelhecimento, o enfermeiro e os demais profissionais envolvidos, devem atuar junto ao idoso e seus familiares, apoiando suas decisões, ajudando-os a aceitar as alterações na imagem corporal quando existentes, em um processo educativo que vise às necessidades individuais.

No que se refere às ações primárias de saúde, considera-se que são de extrema importância, não apenas ao âmbito individual, mas também coletivo, pois contribuem para um estilo de vida saudável, abrangendo a promoção e a proteção da saúde, a prevenção de agravos, o diagnóstico, o tratamento, a reabilitação e a manutenção da saúde (14).

\section{Ações desenvolvidas pelo enfermeiro na Atenção Primária à Saúde}

Com relação às atividades realizadas para promover o bem estar físico-mental e social dos idosos, algumas enfermeiras relatam que fazem mais ações voltadas para a atenção curativa dos idosos, como podemos observar:

“[...] Para atender os idosos a gente procura ver à necessidade dele para elaborar uma boa assistência. A gente faz curativos, testes de glicose, entre outras técnicas para melhor atender o idoso" (Tulipa).

"[...] O nosso fluxo de atendimento é bem intenso, porém quando o idoso vem aqui proporcionamos a ele um atendimento preferencial. A gente realiza o cuidado que o idoso precisa aqui como, curativos, medicações e outros procedimentos técnicos"(Girassol).

Tulipa e Girassol não prestam uma atenção integral ao idoso, atendo-se apenas nas questões de cerne curativo, de modo que a promoção da qualidade de vida, para as respondentes, significa o reconhecimento das alterações biológicas e prestação de uma assistência centrada na patologia e não no indivíduo como ser social.

Para atender aos idosos precisa-se de uma atenção integral e articulada com outros profissionais de saúde, com recursos humanos capacitados que vão atuar nos fatores que alteram o equilíbrio entre o indivíduo e o ambiente, compreendendo a saúde em seu sentido mais abrangente. Para tanto, ele deve buscar conhecer detalhadamente a realidade do idoso e da família, incluindo seus aspectos biológicos, psicológicos sociais (9).

$\mathrm{O}$ cuidado de enfermagem aos idosos deve estar relacionado com ações que envolvam todos os níveis de atenção e, principalmente, envolvendo a família nesse processo. Sobre isso, alguns enfermeiros citaram que incluíam a família em suas ações de saúde:

“[...] Para promover a qualidade de vida dos idosos, a gente trabalha primeiramente com orientações para família, porque a gente acha importante investir nos cuidadores, pois é na 
casa que eles estão na maior parte do tempo" (Rosa).

“[...] Além de realizarmos visitas domiciliares e conhecer a realidade em que a pessoa idosa vive, aqui eu sempre faço orientação para o paciente e para a família, tento fazer eles participarem no cuidado do idoso, pois em sua maioria são eles que são os cuidadores" (Orquídea).

Acreditam que juntamente com os cuidados assistenciais, o vínculo com a família é fundamental para a atenção ao idoso, já que os familiares são vistos como pessoas que necessitam de orientações e, geralmente, acabam atuando como cuidadores. $\mathrm{O}$ enfermeiro promove uma assistência eficaz ao idoso que necessita de cuidados domiciliares ou que possui limitações, doenças crônicas, que exigem um cuidado direto do familiar.

$\mathrm{Na}$ prestação do cuidado ao idoso, há necessidade de conscientização sobre esse período da vida, devendo haver ênfase na promoção da saúde e nas práticas preventivas, objetivando o autocuidado. Assim, é essencial a manutenção de idosos em atividades produtivas na sociedade, o que contribui para seu bem estar físico, mental e social, reduzindo riscos de incapacidades físicas e protelando doenças, impactando positivamente na qualidade de vida. Para tanto, é fundamental que o enfermeiro promova a independência do idoso, assegure sua autonomia, com uma visão integral e direcionando cuidados específicos (12).

Uma dessas práticas que aparecem durante as entrevistas é a formulação de grupos de idosos que podem trazer grandes benefícios à saúde, com grupos de atividades físicas, incluindo atividades leves individuais ou coletivas como: caminhadas de baixa intensidade, viagens turísticas a lazer em geral, que proporcionam melhoria na condição física e psicológica, auxiliando na realização de movimentos do dia-a-dia, tornando esses indivíduos prestativos em seu meio social (17).

Observamos então o entendimento de que em relação aos grupos de idosos, não há um protocolo ou padrão a ser seguido. Alguns enfermeiros delegam o cuidado em saúde para profissionais de outras áreas porque alegam falta de recursos humanos ou até mesmo sobrecarga de trabalho. Contudo, percebe-se que a falta de envolvimento do enfermeiro pode ser explicado pela percepção prioritariamente biológica sobre o processo de envelhecimento, como podemos visualizar nos relatos:

"[...] Aqui tem atividade na igreja para terceira idade em uma quinta feira por mês. O fisioterapeuta trabalha muito com os idosos ensinando exercícios. Sempre que eu posso tento ir lá realizar orientações, mas fica por conta mais do fisioterapeuta mesmo" (Girassol).

“[...] Então nós, no máximo que a gente oferece são os cuidados aqui no posto, até tem um grupo aqui no bairro, mas é a população que organiza. Aqui da unidade um programa diretamente não tem, não tem nada, a gente contribui com o que a gente tem em mãos, mas não tem nada específico" (Margarida).

A prática de atividades com os idosos como exercícios e palestras pode ocorrer à intervenção de enfermagem, selecionando e realizando as ações mais específicas no cuidado com o idoso, tendo como objetivos a prevenção de problemas, a promoção de conforto físico e psíquico e a diminuição da dependência do idoso, tornando-o habilitado a procurar ajuda para atender sua responsabilidade para o autocuidado. E ainda, as intervenções de enfermagem devem ser centradas nas rotinas do idoso, procurando minimizar os problemas relacionados às atividades de vida diária (9).

As ações destinadas a essa faixa etária são provenientes da população e alguns profissionais entrevistados consideram ainda que as atividades de promoção à saúde não são realizadas na unidade de saúde, ou seja, não há grupos de idosos, porém estes grupos são 
estratégias para a busca de uma boa qualidade de vida, mas não é a única ferramenta a ser utilizada pelo enfermeiro, pois sua função neste grupo é identificar alterações específicas e realizar um plano de cuidados integral ao idoso, o que pode ser feito em qualquer lugar tanto na unidade como na casa do idoso.

Já Girassol afirma que há grupos no seu bairro, mas outros profissionais são os responsáveis, como fisioterapeutas. Por consequência disso, a enfermagem fica com uma parte curativa de atenção a este processo de envelhecimento, por ter essa visão mais biológica.

A promoção da saúde, não necessariamente tem que ser realizada nestes grupos, há idosos que não participam e para estes a prática de enfermagem pode estar relacionada à educação em saúde (8). Nessa linha de atuação, consegue promover ações para todos os idosos, lembrando que alguns dos entrevistados promoviam palestras, atividades físicas, orientações e também os grupos de idosos, os quais relatam que estas atividades contribuem para melhorar a qualidade de vida e o bem-estar biopsicossocial:

\section{"[...] Aqui na nossa unidade a gente também} tem um grupos de idosos bem participativos. Eles vêm, participam, fazemos passeios, as festas de fim de ano. E a gente tem bastantes parceiras, como da Unicentro. Os alunos vêm para o estágio e colabora muito, além dos grupos de extensão que trabalham com eles toda a semana. Isso nos ajuda muito e mantêm o nível de cuidado elevado no grupo" (Violeta).

Os passeios, grupos de convivência, ações educativas, práticas de atividades físicas no cotidiano e no lazer foram apontados como estratégias que, além de proporcionarem à pessoa idosa um envelhecimento saudável, o enfermeiro poderá utilizar como elo entre o paciente e a comunidade.

É válido ressaltar a importância de parcerias com as universidades, prefeitura, igrejas, pois as mesmas colaboraram com maiores opções de entretenimento e benefícios mútuos. Neste papel, o enfermeiro deverá atuar como facilitador e propiciar que os membros do grupo exponham suas experiências, valorizando-as, buscando estimular o autocuidado e o enfrentamento das possíveis adversidades relacionadas ao processo de envelhecimento e contribuindo para uma melhor qualidade de vida.

Verifica-se ainda, a necessidade de os profissionais de saúde, em especial os enfermeiros, estarem capacitados para atuar na promoção da saúde, prevenção e reabilitação das doenças crônicas degenerativas, além de estruturar ações de ordem preventiva para atender em atividades sociais, cognitivas e físicas. Como exemplo a formação de grupos de idosos, os quais que estimulam uma vida social e mais saudável com a realização de atividades recreativas, físicas e culturais para propiciar mudanças no comportamento e hábitos diante de situações que apresentem riscos, como os problemas de saúde, hipertensão, diabetes ou aqueles relacionados à sua saúde bucal (18).

\section{CONSIDERAÇÕES FINAIS}

No Brasil há o aumento progressivo da população idosa e o despreparo da rede de saúde pública é evidente, dessa forma, destacamos na pesquisa a falta de um atendimento voltado para as necessidades específicas dos idosos, para abarcar suas particularidades e mudanças ocorridas durante o processo de envelhecimento.

O enfermeiro possui papel de contribuir para que o idoso consiga aumentar os hábitos de vida saudáveis, diminuir e compensar as limitações inerentes da idade e confortarse com a angústia e debilidade da velhice, incluindo o processo de morte. Devido à importância do papel do enfermeiro na saúde pública, principalmente na elaboração de 
ações primárias que visam à promoção da saúde que se realizou esta pesquisa.

Constatamos que a qualidade de vida está ligada à compreensão dos enfermeiros sobre o processo de envelhecimento. Porém, a percepção deve ir além das mudanças biológicas, é necessário pensar no processo de senescência, como um todo e de maneira integral. Enfermeiros realizam apenas cuidados curativos aos idosos por relacionarem o processo de envelhecimento prioritariamente biológico. É de grande importância a implantação de ações pelo enfermeiro, direcionadas à pessoa idosa, adotando políticas que visem mais a natureza promocional e preventiva e menos curativa, contribuindo para o bem estar físico, emocional e social da terceira idade.

Diante do fato de que outras áreas da saúde tratam somente doenças ou as condições que a mesma reflete sobre o indivíduo, a enfermeiro age também na ausência da doença, dessa forma nos mostra a importância do papel deste profissional na saúde pública e, principalmente, focalizado na atenção primária, em que o aprimoramento do ato de cuidar deve ser realizado constantemente, proporcionando um atendimento de qualidade, baseado em conhecimentos científicos atualizados e em uma assistência integral.

\section{REFERÊNCIAS}

1. Secretaria de Atenção a Saúde. Departamento de Atenção Básica. Caderno de Atenção Básica: Envelhecimento e Saúde da pessoa idosa. Brasil 19. Série A: normas e manuais técnicos. Brasília: Ministério da Saúde Brasil; 2006. 192p.

2. Pesquisa Nacional por Amostra de Domicílios. Síntese dos indicadores de 2009. 2010 [Internet]. Brasil: IBGE; 2010 [citado 12 dez 2010]. 43. Disponível em: http://www.ibge.gov.br

3. Souza RF, Skubs T, Brêtas ACP. Envelhe- cimento e família: uma nova perspectiva para o cuidado de enfermagem. Rev Bras Enferm. 2007; 60(3): 263-67.

4. Tavares DMS, Guidetti GECB, Saúde MIBM. Características sócio-demográficas, condições de saúde e utilização de serviços de saúde por idosos. Revista Eletrônica de Enfermagem [Internet]. 2008 [citada12 dez 2010]; 10(2): 299-309. Disponível em: http://www.fen.ufg.br/ fen_revista/v10/n2/pdf/v10n2a02.pdf

5. Lopes FL, Tier Filho CG, Santos SSC. Diagnósticos de enfermagem de idosos residentes em uma instituição de longa permanência (ILP). Cienc Cuid Saude. 2007; 6(1): 59-67.

6. da Silva ACGM, Leite JFR, Paganini MC. Cuidados de enfermagem e o envelhecimento: da prática à reflexão. Boletim de enfermagem. 2007; 1(1): 1-13.

7. Bardin L. Análise de conteúdo. São Paulo: Edições 70; 2011.

8. Hein MA, Aragaki SS. Saúde e envelhecimento: um estudo de dissertações de mestrado brasileiras (2000-2009). Cien Saude Colet. 2012. 17(8): 2141-150.

9. Moraes EN, Moraes FL, Pessoa Lima SPP. Características biológicas e psicológicas do envelhecimento. Rev Assoc Med Minas Gerais. 2010; 20(1): 67-73.

10. Straub RH, Cutolo M, Zietz B, Schölmerich J. The process of aging changes the interplay of the immune, endocrine and nervous systems. Mech Ageing Dev. 2010; 122(14): 1591-611.

11. Schimidt TCG, da Silva MJP. Percepção e compreensão de profissionais e graduandos de saúde sobre o idoso e o envelhecimento humano. Rev Esc Enferm USP. 2012; 46(3): 612-17.

12. Gandolpho MA, Ferrari MAC. A enfermagem cuidando do idoso: reflexões bioéticas. O Mundo Da Saude. 2006; 30(3): 398-408.

13. Oliveira DAAP, Gomes L, Oliveira RF. Prevalência de depressão em idosos que freqüentam centros de convivência. Rev 
Salud Publica. 2006; 40(4): 734-36.

14. Schneider RH, Irigaray TQ. O envelhecimento na atualidade: aspectos cronológicos, biológicos, psicológicos e sociais. Estud. psicol. 2008; 25(4): 585-93.

15. Alvarenga LN, Kiyan L, Bitencourt B, Wanderley KS. Repercussões da aposentadoria na qualidade de vida do idoso. Rev Esc Enferm USP. 2009; 43(4): 796802.

16. Silva MJ, Bessa MEP, Oliveira AMC. Ta- manho e estrutura familiar de idosos residentes em áreas periféricas de uma metrópole. Cienc. enferm. 2004; X(1): 31-9.

17. Ramos LR. O País do Futuro não Pensa no Futuro. Gerontologia. 1995; 3(1): 524.

18. Pilger C, Menon MH, Mathias TA de F. Socio-demographic and health characteristics of elderly individuals: support for health services. Rev. Lat Am. Enfermagem. 2011; 19(5): 1230-238. 